\title{
Design and Realization of Social Responsibility Report Writing System *
}

\author{
HAO Qin \\ Quality Management Branch \\ China National Institute of Standardization \\ Beijing, China \\ haoqin@cnis.gov.cn
}

\begin{abstract}
This paper proposes a guiding tool for companies to write social responsibility report by developing an applicable writing system based on analysis of its functional requirements, writing indicators and roles. The system's operation and results concerned will be demonstrated as well.
\end{abstract}

\section{Keywords—Social Responsibility; Report Writing; System}

Companies should fulfill their social responsibilities, and disclose in time accurate information in this regard to the stakeholders. For this reason, releasing such reports regularly is becoming a stage where companies can fulfill their own social responsibilities and communicate with stakeholders. It is therefore of great importance for each enterprise to interpret the concept, show the image, and represent the value of social responsibility. As companies in China make advance in their social responsibilities, it becomes a trend to write and release reports on this subject [1].

At the same time, we should know that it is a new idea for domestic enterprises to undertake their social responsibility. About release and disclosure of such reports, there are many problems such as oversimplified reports, vague main lines, unclear framework and messy information. Moreover, the information disclosure should be more timely, more objective, better-balanced and more readable. This has two reasons: first, it is a new thing for many companies to do so; second, there is no guiding tool available to domestic companies writing their social responsibility report [2].

To make them further fulfill their social responsibilities for better report quality and effect, it is necessary to develop the report-specific tool on an ad hoc basis of China. In order to prepare more international industry-wide reports as a response to the requirements of this new era, we intend to develop a report writing system in this research; and I hope that the research results can be applied in: standardizing the report writing and improving the quality of social responsibility information for disclosure; deepening the social responsibility management and domestic corporate social responsibility; and, helping corporate stakeholders like government departments and the general public as well as the international community to better understand their social responsibilities.

This Project was supported by the Presidential Foundation of China National Institute of Standardization titled Research and Empirical Analysis of Corporate Social Responsibility Management System (Project No.: 552014Y-3347).

\section{Overall DESIGN AND ANALYSIS OF THE SyStem}

\section{A. Analysis on Functional Needs}

The system is designed with functions including indicator system overview, user entering, report statistics, generation and uploading. The overview can list all the indicators for the social responsibility report. This function enables the user to learn what indicators should be filled in. User entering means the system will, according to each writing indicator, show the entry interface that contains three items: indicator interpretation, example and content. In each indicator's entry, the system can provides the corresponding style template for the user's reference. The report statistics is to perform analytic statistics on the completeness of user-inputted information. Meanwhile, the system will conduct statistical analysis on the indicators about positive and negative sides of corporate social responsibility. Next, the system will automatically write the social responsibility report of the preset structure and format (WORD) for the sake of downloading. Once all the indicators are entered, the data will be uploaded to the server. If the user is not certain about system operation, he or she can view the help page.

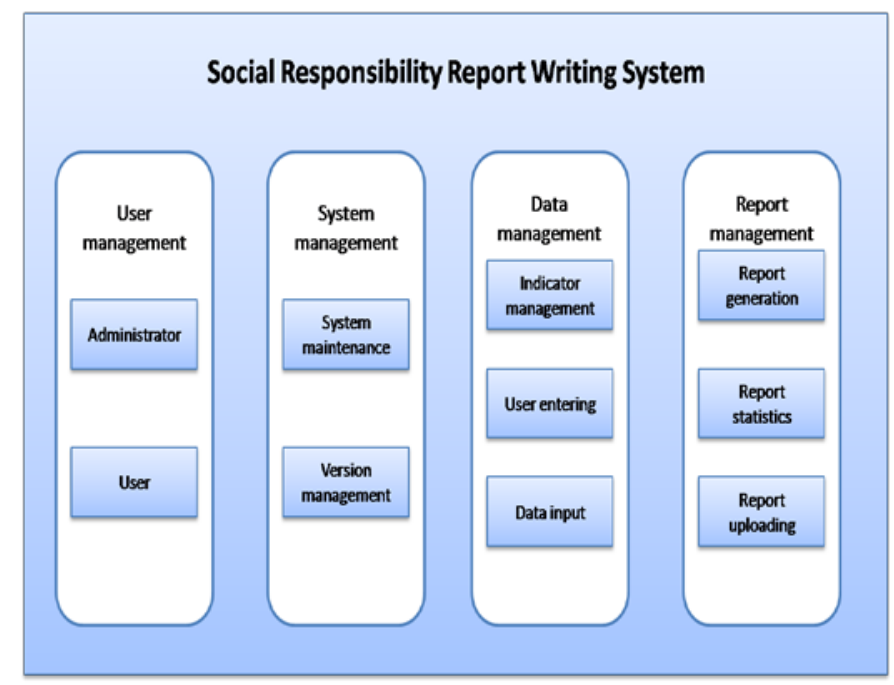

Fig. 1. System Function Chart 


\section{B. Selection of Writing Indicators}

\section{1) Indicator boundary}

On the whole, the indicator boundary for writing the social responsibility report may be defined as the " $1+3+7$ " mode. Where, " 1 " denotes the responsibility to the shareholders; " 3 " refers to triple bottom line: economic (market) performance, social performance and environmental (protection) performance; and "7" stands for division of the core theme based on shareholder expectation: organizational governance, human rights, labor practice, environment, fair operating practice, consumer issues, community participation and development.

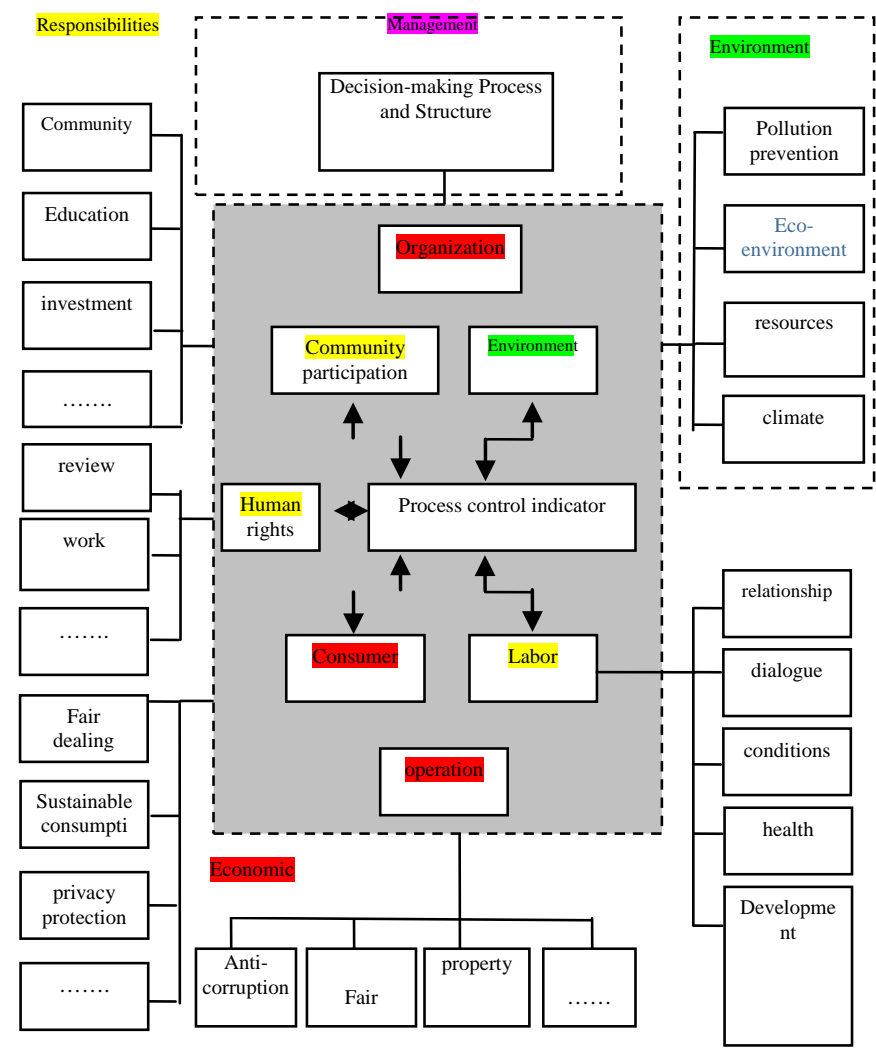

Fig. 2. Indicator Boundary for Writing of the Social Responsibility Report

\section{2) Selection of indicators}

With reference to the research literature at home and abroad, this research orients the report from different angles, and divides it into different types using three first-level indicators to meet the needs for writing a report as much as possible.
TABLE I. SELECTION OF WRITING INDICATORS FOR SOCIAL RESPONSIBILITY REPORT

\begin{tabular}{|c|c|c|}
\hline First-level & \multicolumn{2}{|c|}{ Second-level indicator } \\
\hline \multirow{3}{*}{$\begin{array}{l}\text { Format } \\
\text { indicator }\end{array}$} & Report structural indicator & \multirow{3}{*}{$\begin{array}{l}\text { Consisting of } 17 \text { third- } \\
\text { level indicators }\end{array}$} \\
\hline & Report entity indicator & \\
\hline & Report technical indicator & \\
\hline \multirow{7}{*}{$\begin{array}{l}\text { Basic } \\
\text { information } \\
\text { indicator }\end{array}$} & Company profile & \multirow{7}{*}{$\begin{array}{l}\text { Consisting of } 17 \text { third- } \\
\text { level indicators }\end{array}$} \\
\hline & Report description & \\
\hline & Strategy and governance & \\
\hline & Executives statement & \\
\hline & Shareholders & \\
\hline & $\begin{array}{l}\text { Risk and opportunity } \\
\text { analysis }\end{array}$ & \\
\hline & Contents of plan & \\
\hline \multirow{8}{*}{$\begin{array}{l}\text { Core content } \\
\text { indicator }\end{array}$} & $\begin{array}{l}\text { Identification of } \\
\text { shareholders }\end{array}$ & \multirow{8}{*}{$\begin{array}{l}\text { Consisting of } 217 \text { third- } \\
\text { level indicators, covering } \\
\text { economy, society and } \\
\text { environment as well as } \\
12 \text { shareholders }\end{array}$} \\
\hline & $\begin{array}{l}\text { Requirements and } \\
\text { expectation of shareholders }\end{array}$ & \\
\hline & $\begin{array}{l}\text { Channels and means of } \\
\text { communication }\end{array}$ & \\
\hline & Shareholder-related contents & \\
\hline & $\begin{array}{l}\text { Degree of disclosure aiming } \\
\text { at the issues related to } \\
\text { shareholders }\end{array}$ & \\
\hline & $\begin{array}{l}\text { Shareholders' responsibility } \\
\text { ideas and policies }\end{array}$ & \\
\hline & $\begin{array}{l}\text { Shareholders' responsibility } \\
\text { performance }\end{array}$ & \\
\hline & $\begin{array}{l}\text { Is the shareholders' } \\
\text { responsibility idea related } \\
\text { to the agency’s strategy? }\end{array}$ & \\
\hline
\end{tabular}

\section{Analysis on its Roles and Authority}

In the whole operation, the system should address allocation and management of different roles. That is to say the system should not only differentiate the roles, but also assign them appropriate permissions, so that the system operates well on the business level. To take an overall look, there are two categories: corporate users and system administrators. Fig. 3 shows the correlation between system functional modules in terms of different system roles. The system is oriented to corporate users. Specifically, it offers users functional services, and it also needs to realize the effective interaction between the two. The system administrator mainly maintains the normal operation of the system, and conducts activities of each link. 


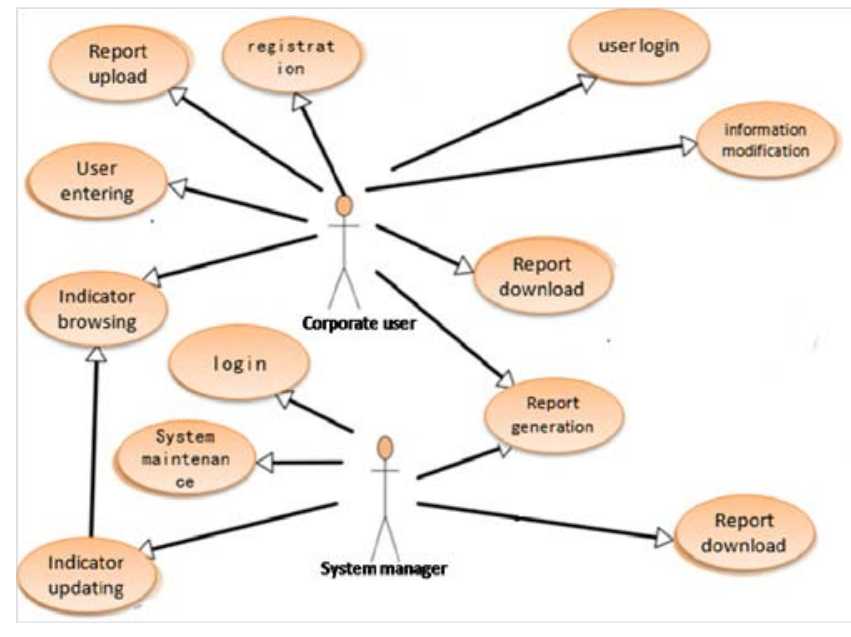

Fig. 3. System User Example Chart

\section{SYSTEM REALIZATION}

\section{A. Operate main interface}

Fig. 4 is the main interface for writing a social responsibility report, including buttons for overview of the indicator system, indicator entering, report statistics, report generation, report uploading and help. The user may enter the appropriate interface as needed.

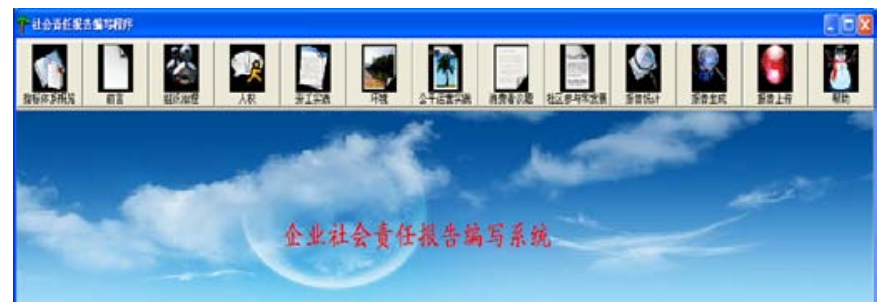

Fig. 4. Main Interface for Writing a Social Responsibility Report

\section{B. User Entering}

Fig. 5 shows the main interface for a user. The organizational governance main interface shown in the figure will appear as long as the organizational governance button is clicked. On such interface, there are 13 buttons available. Click the upper buttons and the corresponding window will pop up. Each window will show the indicator interpretation, example and content. According to the reference, complete the appropriate content in the textbox. To modify the content, just click the modification button. After the content is modified, click the confirmation button. If the user intends to leave any indicator blank, please click the quit button.
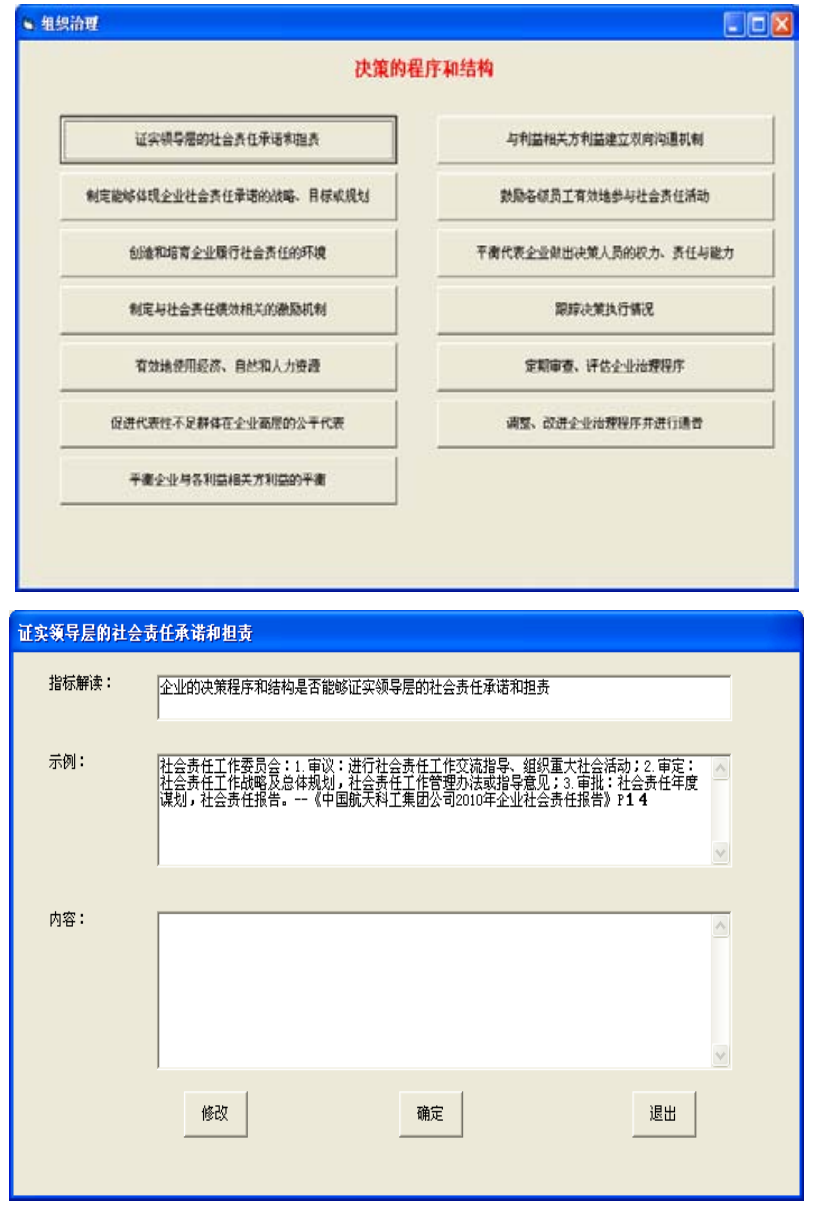

Fig. 5. User Entering Interface of the Social Responsibility Report Writing System

\section{Report Generation}

Fig. 6 indicates the social responsibility report generated by the writing system. The report is automatically generated in terms of the indicator contents and the typography style preset at the same time.

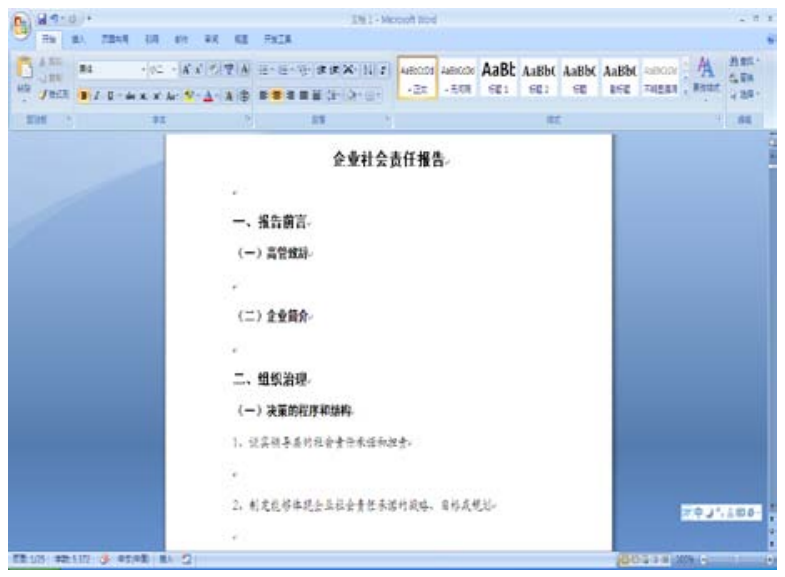

Fig. 6. Report Generated by the Social Responsibility Report Writing System 


\section{REFERENCES}

[1] YIN Gefei, LI Weiyang, "Guidance for Corporate Social Responsibility Report,”M. China Renmin University Press, 2010.

[2] PENG Huagang, "Guidelines on Corporate Social Responsibility Reporting for Chinese Companies 2.0," M. Economic Management Press, 2011. 